\title{
Proceeding
}

11th World Congress of Performance Analysis of Sport, 16-18 November 2016. International Society of Performance Analysis of Sport. Alicante, Spain

\section{Assessment of procedural knowledge in volleyball players}

\author{
JORGE MACÍAS ROMERO, JOSÉ ANTONIO GONZÁLEZ-JURADO, FERNANDO MANUEL OTERO- \\ SABORIDO
}

Pablo Olavide Universitiy, Spain

\begin{abstract}
Procedural knowledge (PK) is an influential in decision-making and technical execution factor in volleyball.The aim of this study was to analyse the effects of applying an observation tool used by volleyball players to assess their procedural knowledge. The research combines quantitative and qualitative methodology.In the quantitative section, which involved a quasi-experimental design with a control group, a total of $20 \mathrm{U}-16$ players were distributed into a control group $(n=10 ; 14.70 \pm 0.67)$ and an experimental group $(n=10 ; 15.00 \pm 0.47)$. The dependent variable was the PK, which was measured using a validated questionnaire. Between the pre-test and post-test of PK, the players belonging to the experimental group observed the game through the Games Performance Assessment Instrument (GPAl) tool. The implementation of the GPAl observation instruments in the experimental groups had four sessions. The group experimental observed whole-games situations of $4 \mathrm{Vs} 4$. In the qualitative part, these players were interviewed about their experience in the process. The results proved that PK improves after the use of GPAI. The experimental group showed statistically significant differences with the control group in the total score of the questionnaire on PK $(p=0.000)$ and in two of the three dimensions (attacking: $p=0.031$; blocking: $p=$ 0.000). Other statistical evidence like effect size or the analysis of covariance confirmed the improvements of the group that used GPAI. In the interviews, the volleyball players attributed their improvements to the learning generated by the observation instrument used. This work demonstrates that tactical training in volleyball players helps to improve procedural knowledge. Key words: DECISION MAKING, TEAM SPORTS, NET GAMES, GPAI.
\end{abstract}

\section{Cite this article as:}

Macías Romero, J., González-Jurado, J.A., \& Otero-Saborido, F.M. (2017). Assessment of procedural knowledge in volleyball players. Journal of Human Sport and Exercise, 12(3proc), S846-S856. doi:https://doi.org/10.14198/jhse.2017.12.Proc3.09

Corresponding author. Pablo Olavide Universitiy, Sevilla, Spain.

E-mail: fmotero@upo.es

11th World Congress of Performance Analysis of Sport, 16-18 November 2016. International Society of Performance Analysis of Sport. Alicante, Spain.

JOURNAL OF HUMAN SPORT \& EXERCISE ISSN 1988-5202

(C) Faculty of Education. University of Alicante

doi:10.14198/jhse.2017.12.Proc3.09

S846 | 2017| Proc3 | VOLUME 12

C 2017 University of Alicante 


\section{INTRODUCTION}

Sport has become for many citizens a much appreciated pastime, even dominant in some cases. This interest has grown in a spectacular way among top-level sports and volleyball is one of the most practised ones with the highest number of federation licenses (Garcia-Ferrando, 2006). It is a team sport conditioned by a strong rule establishing that the ball cannot be stopped or held in the court once the game has started.

It seems that there is a relationship between tactical knowledge and decision-making in sport. Different studies suggest that the training of cognitive processes of tactical knowledge could contribute to decisionmaking in real sport situations. (Figueiredo, Lago, \& Fernández, 2008; French \& Thomas, 2009; GarcíaGonzález, Araújo, Carvalho, \& del Villar, 2011; McPherson \& Kernodle, 2007; A. Moreno, Moreno, GarcíaGonzález, \& Del Villar, 2010; Serra-Olivares \& García-López, 2011).

In this sense, the training of cognitive processes of tactical knowledge (e.g. anticipation) is a good method to improve decision making in real situations. If an athlete anticipates and observes the movements of his adversary it will enable him to adjust his decision-making strategies during the competition (García-González et al., 2011; Mann, Williams, Ward, \& Janelle, 2007). However, the key to training of perceptual-cognitive skills is how to transfer them during the decision making in real game situations (Broadbent, Causer, Williams, \& Ford, 2014). Different studies indicate that age alone does not influence the level of tactical knowledge; it seems that sport expertise is more important (Mann et al., 2007; Marasso, Laborde, Bardaglio, \& Raab, 2014; McPherson \& Kernodle, 2007).

Researches have inquired about training methods and evaluation of tactical knowledge and decision-making in sport. At the tactical knowledge there are tools like analysis verbal protocols, questionnaires and training programmes based on video-feedback. Observational analysis are tools for decision-making (GarcíaGonzález et al., 2011; McPherson \& Kernodle, 2007; Oslin, Mitchell, \& Griffin, 1998).

From the relationship between tactical knowledge and decision-making, and as a consequence of these indications, Anderson (1982) established two types of knowledge: declarative and procedural. In the first case, the "know what" is used to describe declarative knowledge, while, in the second case, the "know how" is used to describe procedural knowledge. The first is understood as a set of theoretical knowledge for a sport, whereas the second, procedural knowledge, is conceived as the knowledge based on the tactical solution in the environments played (Otero, González, \& Calvo, 2012a). According to French and Thomas (2009), the development of a declarative knowledge in a specific sport is essential for the development of good decision-making skills.

Declarative knowledge comprises all the theoretical knowledge of a sport, from the technical-tactical fundamentals to the regulatory aspects. Therefore, when a player shows a reduced declarative knowledge he or she yields low quality decisions in real game situations (French \& Thomas, 2009) "If the volleyball player knows, for example, what the dimensions of the field are or the position of the players, we could say that this player has certain level of declarative knowledge (A. Moreno et al., 2010). On the other hand, besides knowing the theoretical knowledge of the sport, the capability of knowing how to solve a tactical problem posed in theory is defined as procedural knowledge. In the same way García-González (2009) determined in a study that declarative knowledge and procedural knowledge, as measured by questionnaires, have a positive influence on decision-making and implementation variables, thus confirming the importance of the use of questionnaires as measuring instruments. Del Villar et al. (2013) developed and validated a 
questionnaire to assess the influence of procedural knowledge on decision making in volleyball, which was used in this investigation.

Numerous studies state that the knowledge acquired determines the quality of decisions and actions made by the player, causing an increased performance in competition. Therefore, the improvement of declarative and procedural knowledge in sport is of great importance for the achievement of sporting prowess (Iglesias, Moreno, Santos-Rosa, Cervelló, \& Del Villar, 2005).

The use of the Game Performance Assessment Instrument (GPAl) of Oslin et al. (1998) is one of the procedures for analysing decision making (Otero et al., 2012a; Otero-Saborido, Lluch, \& González-Jurado, 2015; Otero-Saborido \& Silva, 2015). This tool qualitatively discriminates the game and allows analysing the quality of the actions of the game. Its application can be used in all team sports, although some categories have to be adapted to the specific characteristics of each form. The use of GPAI helps athletes and / or students to focus on tactical problems specific to procedural knowledge that have been targeted for this study. GPAI is one of the two most used performance instruments in the field of co-evaluation of team (Memmert \& Harvey, 2008). According to the review of Arias and Castejón (2012) GPAl is used in 43.7\% of studies about net sports.

Within volleyball, several technical-tactical actions have gained special attention, among which attacking, serving and blocking are considered the most important of all (Coleman, 2002; Palao, Santos, \& Ureña, 2004). Drikos, et al., (2009) point out that, during a game, ending actions are the ones that exert greatest influence on the performance of a team. Of all the ending actions, attacking is the game action from which more points are awarded in competition, showing a strong connection with victory and becoming the biggest indicator of success in volleyball, followed by serving and blocking (Drikos et al., 2009; Marcelino, Mesquita, \& Sampaio, 2011; Palao et al., 2004; Quiroga et al., 2010; E. A. Ureña, León, \& González, 2013).

Moreover, in recent decades, serving has become the first offensive weapon for players and teams of different levels (A. Ureña, Vavassori, León, \& González, 2011). In addition, it is the first action of the game in which there is an opportunity to score a point (García-Tormo, Jiménez, \& Rábago, 2015; Marcelino, Mesquita, Castro, \& Sampaio, 2008; Quiroga et al., 2010; Rodriguez-Ruiz et al., 2011). On the other hand, blocking is the first action performed by the defending team to try neutralizing the incoming attack (Hileno \& Buscà, 2012; Laporta L Nikolaidis P, Thomas L, 2015). This technical action has increased its importance during the development of the game, especially in women's volleyball (Mosher, 1993).

Considering the previously quoted scientific literature, which states that good procedural knowledge in sport improves tactical decisions in practise, we formulate the following hypothesis:

- A mutual evaluation of tactical decisions by volleyball players improves procedural knowledge.

Thus, the present work aims to test the effects of using an observation instrument (GPAI) in live situations on the procedural knowledge of some of the most determining actions in volleyball such as attacking, serving and blocking.

\section{MATERIAL AND METHODS}

The present research combines quantitative and qualitative methodologies. The quantitative part is a quasiexperimental design, since there is no randomization in the selection of participants, with a transversal 
approach and a nonequivalent control group design with pre post measurements. The interview was used as the data collection technique for the qualitative perspective.

\section{Participants}

A total of $20 \mathrm{U}-16$ players $(14.85 \pm 0.74)$ participated in the research from two local volleyball teams, which were also distributed into a control group $(n=10 ; 14.70 \pm 0.67)$ and an experimental group $(n=10 ; 15.00 \pm$ 0.47 ). Both team participated in the same provincial competition. The ethics committee of the Pablo de Olavide University approved the terms of this investigation.

\section{Instruments and variables}

Three instruments were used in this research: questionnaire, observation tool and interview. The procedural knowledge questionnaire validated by Moreno et al. (2013) was used to measure the dependent variable (Procedural knowledge). This instrument was validated with 486 volleyball players and had high validity values from the perspective of internal consistency. 15 items were selected for the present research. The questions referred to decision making and technical execution during serving, blocking (four questions each) and attacking (eight questions). These technical actions were the ones observed by the players from the experimental groups.

The second instrument, used for the independent variable (Decision-making) in the experimental group, was an observation tool based on the Games Performance Assessment Instrument (GPAl) developed by Oslin, et al. (1998). In the present investigation, the GPAl was used at serving, attacking and blocking. Moreno's design (2011 a; 2011b)adapted from Oslin, et al. (1998) was used for the attacking and serving action. The criteria selected by the FIVB tool were applied to the blocking action (Table 1).

Finally, the third instrument used was the interview. The questions were designed and formulated by the study investigators. The interviews were semi-structured and the questions were designed and formulated by the study investigators. 9 open questions were part of the interview. The opinion of the players on decisionmaking, performance, technique and tactics, procedural knowledge, participation in research and observation tool used were some of the topics of the interview questions.

Table 1. Moreno et al. (2011) adapted from Oslin et al. (1998)

DIMENSIONS: making
decisión and ejecution

\begin{tabular}{|c|c|}
\hline \multirow{3}{*}{ GPAl for attacking } & 1. Attack directed to an open area of the opposite half. \\
\hline & $\begin{array}{l}\text { 2. Attack directed toward an area which is uncovered or poorly covered } \\
\text { by the blocking players. }\end{array}$ \\
\hline & 3. Attack on the block with the aim of achieving block-out. \\
\hline \multirow{2}{*}{ GPAl for blocking } & $\begin{array}{l}\text { 1. The blocked ball returns to the field of the attacking team, scoring a } \\
\text { point. }\end{array}$ \\
\hline & $\begin{array}{l}\text { 2. The blocked ball returns to the defending team, allowing all attacking } \\
\text { options. }\end{array}$ \\
\hline
\end{tabular}


3. The blocked ball returns to the attacking team, preventing all attacking options. The attacking team then sends the ball from low hand or fingers to the team that performed the block.

1. The player sends the ball to areas of interference between players, near field lines, or areas involving displacement and contact at movement by the players.

GPAl for serving

2. The player sends the ball to the attacking players making it difficult for them to attack.

3. The player sends the ball to the setter or to areas where the performance of the different placement options are difficult.

With regards to the influence of extraneous variables it should be noted that both teams were in the same competition. Both coaches were informed of the investigation procedure. Game situations used by both teams during training sessions were identical.

\section{Procedure}

The investigation lasted six sessions in both groups (including pre-test and post-test). The pre-test and posttest was applied using the procedural knowledge questionnaire validated by Moreno, et al. (2013). The control and experimental groups performed four weekly training sessions. The length of each session was about 45 minutes. Whole-games situations similar were used in each session of both groups. The coach and players of the experimental group were informed of the objectives of the investigation and they were given an informed consent.

The implementation of the GPAl observation instruments (Oslin et al., 1998) in the experimental groups had four sessions. The first one was used to explain the tool and to answer questions about observation. During the following sessions, the groups were observed through GPAl tool.

The players of the experimental group used the observation instrument to evaluate their teammates in 3 different sessions of 45 minutes each. During each session, the players were divided into 2 groups of 4 players each. In order to carry out the observation, they played $4 \mathrm{vs.} 4$, while the remaining 2 players watched how they played. After 4 minutes, one player of each team left the game and the players who were watching entered the game; and so on until the 3 actions chosen for this study (serving, blocking and attacking) were studied.

Once this training process was over, both the control and experimental groups undertook the post-test that involved a procedural knowledge questionnaire. Finally, those players who used the GPAl were interviewed in order to know their thoughts and opinions about the procedure and what they might have learned from it.

The interviews were semi-structured and the questions were designed and formulated by the study investigators. Before the questionnaires were carried out, the players were informed of the aim of the study. Each interview lasted about half an hour. The interviews were recorded and later transcribed for analysis. 


\section{Statistical analysis and processing of qualitative data}

SPSS V.18 software was used to analyse the collected data. The Shapiro-Wilk test was performed to establish the normality of each variable and the Levene's test for homogeneity of variance in intergroup comparison. To compare the differences between pretest and posttest, a paired sample T-test was conducted. For intergroup comparisons, an independent sample T-test was conducted. Two strategies were used to assess the effects of using GPAl on procedural knowledge. Firstly, the "change" value was obtained as the difference between the scores from the post-test and pre-test. Secondly, analyses of covariance (ANCOVA) with the same independent variable were performed, although using the post-test scores as the dependent variable and the pre-test scores as a covariate. The effect size (ES) was calculated for comparisons made, according to the procedure proposed by Cohen (1988), considering the following criteria: $>0.2$ (small), $>0.5$ (medium), and $>0.8$ (large). The significance level was set to a value of $p \leq 0.05$, and the confidence limits of $95 \%$ were calculated for all measures. QSR NVivo 9 software was applied to classify qualitative data from interviews and to make these coherent.

\section{RESULTS}

The descriptive statistics of the control and experimental groups show that both groups started from low initial levels of procedural knowledge. This is verified in the total scores, and the three dimensions (serving, attacking and blocking). To check whether the procedural knowledge of the players had improved along the study, the scores of the pre-test and post-test were compared using a T-test for related samples. The experimental group showed a statistically significant improvement in the total score of the questionnaire on procedural knowledge in the three dimensions of questions. The T-test for related samples in the control group showed that there were no improvements in the total score or in any of its dimensions. The pre-test of both groups shows no statistically significant differences in neither the total score (Table 2).

Table 2. Comparison intragroups and differences between groups in pretest

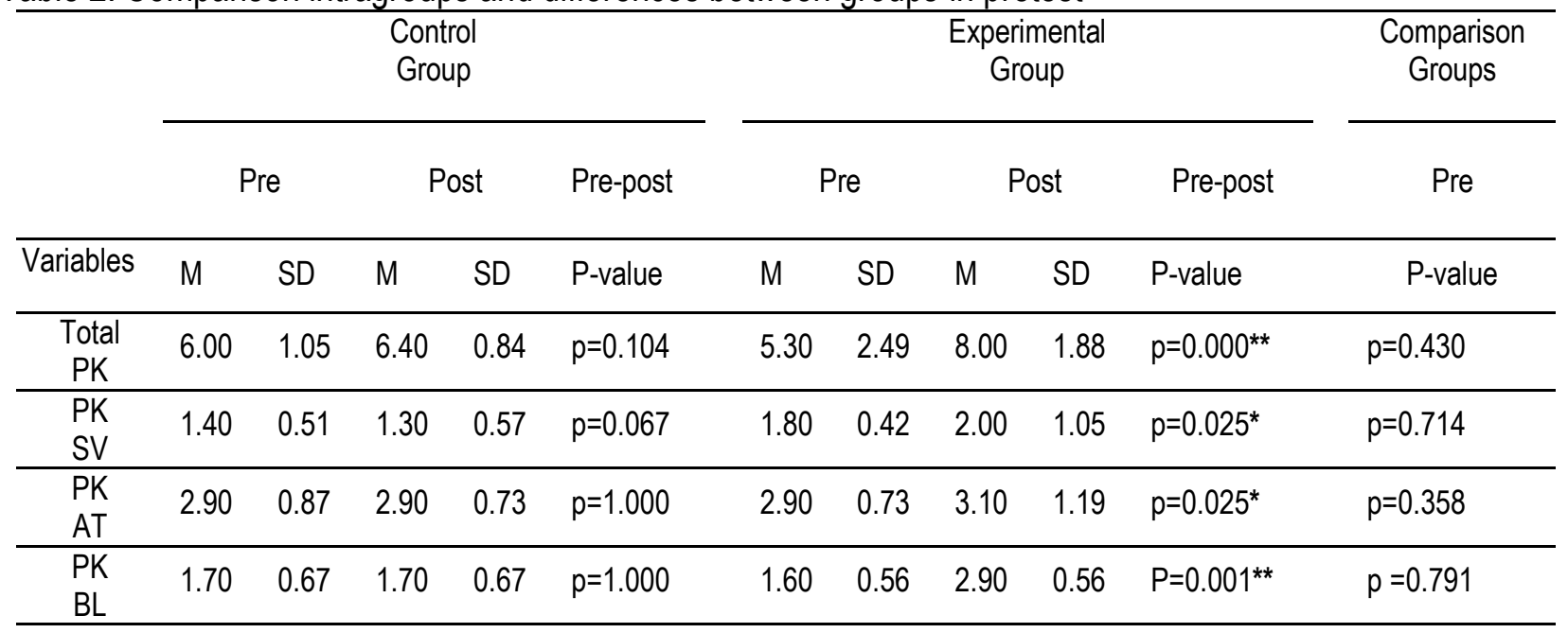

PK: Procedural Knowledge; SV: Serving; AT: Attacking; BL:Blocking; M: Mean; SD: Standard Deviation

${ }^{*} p<0.05 ;{ }^{* *} p<0.001$ (Student's $T$ test). 
However, the main objective of this study was to determine whether there were differences in the development of procedural knowledge between the experimental group and the control group that might be attributable to the intervention. For this, the "difference" variables were compared between the scores from the post-test and pre-test (Table 3 ) of both groups using t-tests for independent samples.

Table 3. Comparison of the variable 'Pre-post difference' between control and experimental group

\begin{tabular}{|c|c|c|c|c|c|c|c|c|}
\hline \multirow[b]{2}{*}{ Variables } & \multicolumn{2}{|c|}{$\begin{array}{l}\text { Control } \\
\text { Group }\end{array}$} & \multicolumn{2}{|c|}{$\begin{array}{c}\text { Experimental } \\
\text { Group }\end{array}$} & \multirow{2}{*}{$\begin{array}{r}\begin{array}{r}\text { Comparison } \\
\text { Groups }\end{array} \\
\text { P-value }\end{array}$} & \multirow{2}{*}{$\frac{\text { Covariance }}{\text { P-value }}$} & \multirow{2}{*}{$\begin{array}{l}\text { Efect } \\
\text { Size (d) }\end{array}$} & \multirow[t]{2}{*}{ Magnitude } \\
\hline & $M$ & SD & $M$ & SD & & & & \\
\hline $\begin{array}{l}\text { Total } \\
\text { PK }\end{array}$ & 0.40 & 0.69 & 2.70 & 0.94 & $p=0.000^{* *}$ & $p=0.000^{* *}$ & 2.88 & Large \\
\hline $\begin{array}{l}\mathrm{PK} \\
\mathrm{SV}\end{array}$ & 0.40 & 051 & 0.70 & 0.82 & $p=0.342$ & $p=0.388$ & 0.43 & Small \\
\hline $\begin{array}{l}\text { PK } \\
\text { AT }\end{array}$ & 0.00 & 0.47 & 0.70 & 0.82 & $p=0.031^{*}$ & $p=0.045^{\star}$ & 1.07 & Large \\
\hline $\begin{array}{l}\text { PK } \\
\text { BL }\end{array}$ & 0.00 & 0.47 & 1.30 & 0.82 & $p=0.000^{* *}$ & $p=0.000^{* *}$ & 1.94 & Large \\
\hline
\end{tabular}

PK: Procedural Knowledge; SV: Serving; AT: Attacking; BL:Blocking; M: Mean; SD: Standard Deviation ${ }^{*} p<0.05 ;{ }^{* *} p<0.001$ (Student's T test).

Although learning was achieved in both groups, the results of the variable 'difference' between pre-test and post-test showed a more positive improvement for the group in which the GPAl tool was applied during the training compared to the control group. Specifically, there was a significant difference in the total score (of the questionnaire on procedural knowledge and in two of the three dimensions (attacking and blocking).

The score of the 'Pre-Post difference' variable shows that while in the intervention group there was an average gain of 2.70 points in the total score, the average gain for the control group was only 0.40 points. If the same analysis is conducted with the dimensions of the questionnaire (serving, attacking, blocking), it shows that, at a descriptive level, the gain is greater in the intervention group for all three dimensions.

In order to provide additional analytical evidence, a second strategy based on the use of analysis of covariance (ANCOVA) was applied, with the post-test scores as the dependent variable, the pre-test scores as covariates and the intervention as an independent variable. The aim was to compare whether there were significant differences between groups considering the previous level of the subjects. The results are completely consistent with the analysis of the 'pre-post Difference' scores, since significant differences are obtained in the total score and in the attacking and blocking dimensions. Finally, the effect size estimates show large efficiency for the intervention group in total score, blocking and attacking.

\section{Qualitative analysis}

After carrying out the content analysis, the most commented aspects by the players were performance $(\mathrm{N}=$ $30)$, observation of the game $(N=26)$, tactics $(N=19)$ and technique $(N=15)$. Interviewed players were informed that they had improved their levels of procedural knowledge with respect to the group that did not use the observation sheet (GPAl). In this line, the players attributed their improvement to the use of the tool and a better understanding of the game: 
"I have improved my performance because I knew more tactics after observing. Once I observed with the sheet I noticed and understood many things about tactics that I did not understand before" (Player 6)

Also, the observation tool is considered very important to avoid making subsequent mistakes.

"I think it's pretty good because you watch the mistakes made by your teammates and you write them down, so you try not to make the same mistakes again" (Player 3)

\section{DISCUSSION}

The hypothesis formulated in this study suggests that mutual evaluation of tactical decisions performed by the players themselves improves their procedural knowledge. The results of the present study confirm this hypothesis, since the players in the experimental group showed greater differences in the post-test than the players from the control group.

Moreover, the views of the interviewed players suggest two ideas. First, their empathy with the GPAl; that is, the players, who are sometimes reluctant to interfere with external investigations they do not know, have shown such great willingness and interest in the study that some of them even requested help from the researchers for the design of other observation tools to incorporate them into their daily training routine. And second, their improvement after the procedural questionnaire was unanimously attributed in the interviews to the use of the observation instrument.

With respect to the process of research and intervention in the experimental group, the researchers suggested that a greater number of sessions would yield better results. In similar study Figueiredo, et al. (2008) obtained values slightly greater than the ones from the present investigation, although this may be related to the number of sessions, which were 25 and 15 , respectively, compared to the 4 sessions of this work. However, greater numbers of sessions also corresponded to a large load of contents, which was included in both studies (technical execution, decision making, declarative knowledge...). Therefore, including more sessions in the present investigation would have required the inclusion of other actions besides the three used (serving, attacking and blocking.)

The importance of procedural knowledge, understood as tactical decisions in the game set out to the player in a theoretical environment, is being widely used in other team sports such as football and basketball (Del Villar, Iglesias, Moreno, Fuentes, \& Cervelló, 2004; Iglesias et al., 2005; Otero, González, \& Calvo, 2012b). However, it is in volleyball where more research is proliferating (Figueiredo et al., 2008; Gil et al., 2012; Al. Moreno et al., 2013). The measurement of the general procedural knowledge of the game through questionnaires can be used as an indirect indicator of the tactical ability of the athlete (García-Gonzalez et al., 2009). For the improvement of tactical skills, it has been demonstrated that showing video sequences of different attacking actions facilitates the recognition of similar patterns in other team sports (Vaeyens, Lenoir, Williams, Mazyn, \& Philippaerts, 2007; Williams, Heron, Ward, \& \& Smeeton, 2004)

In that line of research, the literature has already confirmed that the acquisition of good procedural knowledge influences the improvement of decision-making in the game. Considering the need for giving importance to decision making, the present research had as a priority the observation and analysis of three specific actions: serving, attacking and blocking. Supporting this selection of actions, Palao and Ortega (2015) analysed and compared the frequency and effectiveness of technical and tactical actions between winning and losing teams. Their results showed that winning teams differ from losing teams by ending actions such as the serves that do not allow attacking options, blocking points or counterattacks. This paper uses a reduced sample. For 
this reason, as prospective future research, the research could be replicated in larger samples and be measured as an independent variable 'making-decisions 'in real game situations.

\section{CONCLUSIONS}

In the present study, we have concluded that procedural knowledge (determining factor in making decisions during the game) improves after the application of an intervention program in U-16 players. Likewise, in the interviews, the participants attributed their improvements to the learning generated by the observation instrument used. As a limitation, the use of a natural sample, and therefore a quasi-experimental design, was controlled with the pre-tests (no significant differences between the two groups) and the covariance. However, in future investigations, it will be interesting to randomise the selection of participants.

Likewise, it would be necessary, as a continuation of the present study, to carry out a subsequent investigation to assess whether an intervention program with an observation instrument influences the improvement of decision-making in the game field.

\section{REFERENCES}

1. Anderson, J. R. (1982). Acquisition of cognitive skill. Psychological Review, 89(4), 369-406. http://doi.org/10.1037/0033-295X.89.4.369

2. Arias, J. L., \& Castejón, F. J. (2012). Review of the instruments most frequently employed to assess tactics in physical education and youth sports. Journal of Teaching in Physical Education, 31(4), 381-391. https://doi.org/10.1123/itpe.31.4.381

3. Broadbent, D. P., Causer, J., Williams, a. M., \& Ford, P. R. (2014). Perceptual-cognitive skill training and its transfer to expert performance in the field: Future research directions. European Journal of Sport Science, 1391(January 2016), 1-10. http://doi.org/10.1080/17461391.2014.957727

4. Cohen, J. (1988). Statistical Power Analysis for the Behavioral Sciences (2 ed.). Hillsdale, NJ: Erlbaum Associates.

5. Coleman, J. (2002). The volleyball coaching Bible. In D. Reynaud \& S. C. (Eds.), The volleyball coaching Bible (pp. 321-345). Champaign, IL: : Human Kinetics.

6. Del Villar, F., Iglesias, D., Moreno, M. P., Fuentes, J. P., \& Cervelló, E. M. (2004). An investigation into procedural knowledge and decision-making: Spanish experienced-inexperienced basketball players differences. Journal of Human Movement Studies, 46(5), 407-420.

7. Drikos, S., Kountouris, P., Laios, A., \& Laios, Y. (2009). Correlates of Team Performance in Volleyball. International Journal of Performance Analysis in Sport, 9(2), 149-156. http://doi.org/10.1080/24748668.2009.11868472

8. Figueiredo, L. M., Lago, C., \& Fernández, M. A. (2008). Analysis of the effect of a model of mutual evaluation on the learning of team sports in the school context. Motricidad European Journal of Human Movement, 21, 99-117.

9. French, K. E., \& Thomas, J. R. (2009). The relation of knowledge development to children's basketball performance. Journal of Sport Psychology, 9, 15-32. https://doi.org/10.1123/jsp.9.1.15

10. García-Ferrando, M. (2006). Twenty-five years of analysis of the spanish population sportive behaviour (1980-2005). Revista Internacional de Sociología, 44, 15-38.

11. García-González, L., Araújo, D., Carvalho, J., \& del Villar, F. (2011). Panorámica de las teorías y métodos de investigación en torno a la toma de decisiones en el tenis. Revista de Psicologia Del Deporte, 20(2), 645-666. 
12. García-Gonzalez, L., Moreno, M. P., Moreno, A., \& Iglesias, D. (2009). Relation between knowledge and decision making in tennis players and its influence in sport expertise. Revista Internacional de Ciencias Del Deporte, 17(5), 60-75. http://doi.org/10.5232/ricyde2009.017.05

13. García-Tormo, J. V., Jiménez, A. V., \& Rábago, J. C. M. (2015). Methodological proposal for the quantification and analysis of the level of risk assumed in volleyball service execution in female highlevel competition. Journal of Physical Education and Sport, 15(1), 108-113. http://doi.org/10.7752/ipes.2015.01018

14. Gil, A., del Villar Álvarez, F., Claver Rabaz, F., Moreno Domínguez, A., García González, L., \& Moreno Arroyo, M. P. (2012). Is there a relationship between level of competition and knowledge in volleyball? Retos: Nuevas Tendencias En Educación Física, Deporte Y Recreación, (21), 53-57.

15. Hileno, R., \& Buscà, B. (2012). Observational tool for analyzing attack coverage in volleyball. Revista Internacional de Medicina Y Ciencias de La Actividad Fisica Y Del Deporte, 12(47), 557-570.

16. Iglesias, D., Moreno, M. P., Santos-Rosa, F. J., Cervelló, E. M., \& Del Villar, F. (2005). Cognitive expertise in sport: Relationships between procedural knowledge, experience and performance in youth basketball. Journal of Human Movement Studies, 49(1), 065-076.

17. Laporta L Nikolaidis P, Thomas L, A. (2015). Attack Coverage in High-Level Men's Volleyball: Organization on the Edge of Chaos? Journal of Human Kinetics, 47, 249-257. https://doi.org/10.1515/hukin-2015-0080

18. Mann, D. T., Williams, A. M., Ward, P., \& Janelle, C. M. (2007). Perceptual-cognitive expertise in sport: a meta-analysis. Journal of Sport \& Exercise Psychology, 29(4), 457-78. Retrieved from http://www.ncbi.nlm.nih.gov/pubmed/17968048 https://doi.org/10.1123/jsep.29.4.457

19. Marasso, D., Laborde, S., Bardaglio, G., \& Raab, M. (2014). A developmental perspective on decision making in sports. International Review of Sport and Exercise Psychology, 7(1), 251-273. http://doi.org/10.1080/1750984X.2014.932424

20. Marcelino, R., Mesquita, I., Castro, J., \& Sampaio, J. (2008). Sequential analysis in volleyball attack performance: A log-linear analysis. Journal of Sports Sciences, 26(2), 83-84.

21. Marcelino, R., Mesquita, I., \& Sampaio, J. (2011). Effects of quality of opposition and match status on technical and tactical performances in elite volleyball. Journal of Sports Sciences, 29(7), 733-41. http://doi.org/10.1080/02640414.2011.552516

22. McPherson, S. L., \& Kernodle, M. (2007). Mapping two new points on the tennis expertise continuum: tactical skills of adult advanced beginners and entry-level professionals during competition. Journal of Sports Sciences, 25(8), 945-959. http://doi.org/10.1080/02640410600908035

23. Memmert, D., \& Harvey, S. (2008). The game performance assessment instrument (GPAI): Some concerns and solutions for further development. Journal of Teaching in Physical Education, 27, 220240. https://doi.org/10.1123/itpe.27.2.220

24. Moreno, A., Del Villar, F., García-González, L., Gil-Arias, A., \& Moreno, M. P. (2011). Intervención en la toma de decisiones en jugadores de voleibol en etapas de formación. Revista de Psicología Del Deporte, 20(2), 785-800. http://doi.org/10.1017/CBO9781107415324.004

25. Moreno, A.; Del Villar, F.; García-González, L.; García-Calvo, T.; Moreno, M.P. (2013). Propiedades psicométricas de un cuestionario para la evaluación del conocimiento procedimental en voleibol (CCPV). RICYDE. Rev. int. cienc. deporte. 30(9), 38-47. http://dx.doi.org/10.5232/ricyde2013.03103

26. Moreno, A., Moreno, M. P., García-González, L., \& Del Villar, F. (2010). Development and validation of a questionnaire for assessing declarative knowledge in volleyball. Motricidad. European Journal of Human Movement, 25, 183-195.

27. Moreno, M., Moreno, A., García-González, L., Gil, A., Claver, F., \& Del Villar, F. (2011b). Development of Cognitive Tools for Detection, Tracking and. Archivos de Medicina Del Deporte, 26(146), 435-446. 
28. Mosher, M. (1993). Canadien voleibol association. In Coaches Manual: Level (Ed.), Canadien voleibol association (pp. 3-22). Gloucester : Ontario.

29. Oslin, J. L., Mitchell, S. A., \& Griffin, L. L. (1998). The Game Performance Assessment Instrument (GPAl): Development and Preliminary Validation. Journal of Teaching in Physical Education, 7(2), 231-243. https://doi.org/10.1123/itpe.17.2.231

30. Otero, F. M., González, J. A., \& Calvo, A. (2012a). Validación de instrumentos para la medición del conocimiento declarativo y procedimental y la toma de decisiones en el fútbol escolar. Retos: Nuevas Tendencias En Educación Física, Deporte Y Recreación, (22), 65-69.

31. Otero, F. M., González, J. A., \& Calvo, A. (2012b). Validation tools for measuring procedural and declarative knowledge and assessing decisions in school european football. Retos. Nuevas Tendencias En Educación Física, Deporte Y Recreación, 22, 65-69.

32. Otero-Saborido, F. M., Lluch, Á., \& González-Jurado, J. A. (2015). Student precision and reliability of the team sport assessment in basketball: A primary education case study. South African Journal for Research in Sport, Physical Education and Recreation, 37(2), 83-94.

33. Otero-Saborido, F. M., \& Silva, J. (2015). Reliability of the observation of futsal using team sport assessment procedure (team sport assessment procedure). Revista Iberoamericana de Psicologia Del Ejercicio Y El Deporte, 10(2), 259-266.

34. Palao, J. M., \& Ortega, E. (2015). Skill efficacy in men's beach volleyball. International Journal of Performance Analysis in Sport, 15(1), 125-134. http://doi.org/10.1080/24748668.2015.11868781

35. Palao, J. M., Santos, J. A., \& Ureña, A. (2004). Effect of team level on skill performance in volleyball. International Journal of Performance Analysis in Sport, 4(2), 50-60. http://doi.org/10.1080/24748668.2004.11868304

36. Quiroga, M. E., Garcia-Manso, J. M., Rodriguez-Ruiz, D., Sarmiento, S., De Saa, Y., \& Moreno, M. P. (2010). Relation between in-game role and service characteristics in elite women's volleyball. Journal of Strength and Conditioning Research, 24(9), 2316-2321. http://doi.org/10.1519/JSC.0b013e3181e3812e

37. Rodriguez-Ruiz, D., Quiroga, M. E., Miralles, J. A., Sarmiento, S., de Saá, Y., \& García-Manso, J. M. (2011). Study of the Technical and Tactical Variables Determining Set Win or Loss in Top-Level European Men's Volleyball. Journal of Quantitative Analysis in Sports, 7(1). http://doi.org/10.2202/1559-0410.1281

38. Serra-Olivares, J. y García-López, L.M. (2016). Diseño y validación del test de conocimiento táctico ofensivo en fútbol (TCTOF) / Design and Validation of the Soccer Tactical Knowledge Test (STKT). Revista Internacional de Medicina y Ciencias de la Actividad Física y el Deporte vol. 16 (62) pp.521536. http://dx.doi.org/10.15366/rimcafd2016.63.008

39. Ureña, A., Vavassori, R., León, J., \& González, M. (2011). Jump serve incidence on the attack phase in the Spanish under-14 volleyball. RICYDE. Revista Internacional de Ciencias Del Deporte, 7(26), 384-392. http://doi.org/10.5232/ricyde2011.02604

40. Ureña Espa, A.; León, J. y González, M. (2013) Estudio sobre la continuidad del juego en el voleibol masculino infantil / Study about game continuity in children's volleyball. Revista Internacional de Medicina y Ciencias de la Actividad Física y el Deporte vol. 13 (49) pp. 149-162.

41. Vaeyens, R., Lenoir, M., Williams, A., Mazyn, L., \& Philippaerts, R. M. (2007). The effects of task constraints on visual search behavior and decision-making skill in youth soccer players. Journal of Sport and Exercise Psychology, 29(2), 147-169. https://doi.org/10.1123/jsep.29.2.147

42. Williams, A. M., Heron, K., Ward, P., \& \& Smeeton, N. J. (2004). No Using situational probabilities to train perceptual and cognitive skill in novice soccer players. Journal of Sports Sciences, 22, 575576. 